University of Nebraska - Lincoln

DigitalCommons@University of Nebraska - Lincoln

\title{
Differential impacts of wildfire on the population dynamics of an old-forest species
}

Jeremy T. Rockweit

Colorado State University, rockweit@rams.colostate.edu

Alan B. Franklin

USDA/APHIS/WS National Wildlife Research Center, alan.b.franklin@aphis.usda.gov

Peter C. Carlson

Colorado State University

Follow this and additional works at: https://digitalcommons.unl.edu/icwdm_usdanwrc

Part of the Life Sciences Commons

Rockweit, Jeremy T.; Franklin, Alan B.; and Carlson, Peter C., "Differential impacts of wildfire on the population dynamics of an old-forest species" (2017). USDA Wildlife Services - Staff Publications. 1958. https://digitalcommons.unl.edu/icwdm_usdanwrc/1958

This Article is brought to you for free and open access by the U.S. Department of Agriculture: Animal and Plant Health Inspection Service at DigitalCommons@University of Nebraska - Lincoln. It has been accepted for inclusion in USDA Wildlife Services - Staff Publications by an authorized administrator of DigitalCommons@University of Nebraska - Lincoln. 


\title{
Differential impacts of wildfire on the population dynamics of an old-forest species
}

\author{
Jeremy T. Rockweit iD ${ }^{1,3}$ Alan B. Franklin, ${ }^{2}$ and Peter C. Carlson ${ }^{1}$ \\ ${ }^{1}$ Cooperative Fish and Wildlife Research Unit, Colorado State University, 1484 Campus Delivery, Fort Collins, Colorado 80523 USA \\ ${ }^{2}$ National Wildlife Research Center, USDA, 4101 Laporte Ave., Fort Collins, Colorado 80521 USA
}

\begin{abstract}
Ecological disturbances shape and maintain natural communities, but climate change and human land use can alter disturbance regimes and affect population persistence and vital rates in unpredictable ways. Species inhabiting landscapes shaped by wildfire have evolved mechanisms allowing them to persist under this dynamic disturbance type, which creates habitats of varying quality for these species. We utilized data from a 26-yr demographic study of northern spotted owls to analyze the influence of wildfire on apparent survival and recruitment rates. Wildfires occurred across different years and affected different spotted owl territories, which allowed us to implement a retrospective Before-After-Control-Impact (BACI) analysis and model the potential effect of wildfire extent and severity. Our results indicated that mixed-severity fires that burned at predominantly low-severity had little effect on survival and recruitment while fires characterized by more medium to high burn severities negatively affected spotted owl survival, with varying effects on recruitment. Reduced survival and increased recruitment rates on some territories affected by medium to high severity fires suggested that post-fire habitat quality was reduced resulting in territories that were marginally capable of supporting owls. We hypothesize these territories may have represented "sinks" that were supported by nearby "source" territories in a spatially heterogeneous landscape created by the mixed-severity fire regime of the region.
\end{abstract}

Key words: apparent survival; mixed-severity; population dynamics; recruitment; spotted owl; Strix occidentalis; wildfire.

\section{INTRODUCTION}

Ecological disturbances play an integral role in shaping and maintaining natural communities. Disturbance regimes occur across multiple spatial and temporal scales and can have both positive and negative effects on the plant and animal species they impact (Rykiel 1985) by, for example, creating habitat conditions that improve vital rates (Fraterrigo and Rusak 2008). As such, species have evolved a set of life history traits adapted to coping with disturbance regimes common to their particular ecosystem. Moreover, the degree to which a species or community is affected by disturbance depends on the intensity of the disturbance, the pre-disturbance conditions, and the quality of the surrounding landscape (Franklin et al. 2002). Thus, a species' ability to respond to a disturbance event may be compromised if the dominant disturbance regime is altered from its historic range of variability (e.g., in scale, intensity, frequency, or type of disturbance) due to past land use practices and climate change.

Wildfire is one such disturbance type that has resulted in fire-adapted ecological communities throughout large

Manuscript received 14 October 2016; revised 19 February 2017; accepted 24 February 2017. Corresponding Editor: Evan G. Cooch.

${ }^{3}$ E-mail: rockweit@rams.colostate.edu portions of the western U.S. However, the scale (Stephens 2005, Miller et al. 2012) and intensity (Lutz et al. 2009, Miller et al. 2009) of wildfire has been increasing over the past several decades and is causing considerable concern because of the potential for an increased loss of economically and ecologically valuable forests (Thomas et al. 1990, Davis et al. 2011, USFWS 2011). This increase is thought largely to stem from the unintended consequences of effective fire suppression beginning in the early-to-mid 20th century, past and current timber harvest practices such as clear cut logging (Odion et al. 2004), and the growing influence of climate change (Liu et al. 2013, Abatzoglou and Williams 2016, Westerling 2016).

In the southern portion of the Pacific Northwest lies the Klamath Ecological Province of northwestern California and southwestern Oregon, which is considered a global hotspot for biological diversity (Whitakker 1960). Forests in this region are structurally complex and species rich, with a diverse mix of under- and mid-story hardwood species and a canopy of mixed conifer species (Whitakker 1960, Skinner et al. 2006). This high level of biodiversity is partly a function of the dominant disturbance regime of the area, mixed-severity wildfire, which historically had a relatively frequent fire return interval (12-19 yr; Agee 1993, Willis and Stuart 1994). Prior to fire suppression and timber harvesting, this landscape contained a mosaic of seral stages resulting from mixedseverity wildfires (Perry et al. 2011, Hessburg et al. 
2016). Although high severity patches occurred, they generally were smaller in extent and contributed to the seral stage patchwork that made up the landscape (Skinner et al. 2006, Donato et al. 2009, Halofsky et al. 2011, Perry et al. 2011). One species to capitalize on this patchwork landscape created by wildfire was the northern spotted owl (Strix occidentalis caurina). Although generally considered an old-growth forest obligate, high quality habitat for northern spotted owls in the Klamath Province encompasses a range of different seral stages that balance early seral stages with older forest in a mosaic that mimics the landscape created by mixedseverity fires (Franklin et al. 2000). This patchwork of seral stages (Fig. 1a) and the relatively short fire return interval combine to create a dynamic landscape for the wildlife species inhabiting the region.

This confluence of ecologically and economically valuable forests with a changing disturbance regime has created intense interest in the effects of wildfire on spotted owls, with some studies reporting negative effects of wildfires on spotted owl survival (Clark et al. 2011), reproduction (Gaines et al. 1997, Jenness et al. 2004), and territory occupancy and colonization rates (Clark et al. 2013, Jones et al. 2016) while others found no discernible effects of wildfires on spotted owl survival and reproduction (Bond et al. 2002), territory occupancy (Bond et al. 2002, Roberts et al. 2011, Lee and Bond 2015), and colonization and extinction rates of territories (Lee et al. 2012). Research has also been ambiguous on the use of burned areas by spotted owls; two studies found spotted owls using forests burned at all severities for foraging but avoiding moderate- and high-severity burned areas for roosting (Bond et al. 2009, 2016), one study found the probability of use decreasing with increasing fire severity (Eyes 2014), while another found spotted owls avoided foraging in large patches of severely-burned forest $1 \mathrm{yr}$ post-fire (Jones et al. 2016). These conflicting results suggest that any categorical conclusion about the influence of wildfire on spotted owls is not warranted, but rather that spotted owls exhibit varied responses to wildfire due in part to the highly variable nature of wildfire itself (e.g., overall burn severity, wildfire size, pre-fire habitat conditions, time since fire, etc.) and the methodologies used to analyze their response (occupancy vs. demography vs. habitat use). Furthermore, many of the studies to date are either confounded by post-fire salvage logging (Bond et al. 2009, Clark et al. 2011, 2013, Lee et al. 2012), lack pre-fire data (Gaines et al. 1997, Bond et al. 2002, 2009, Clark et al. 2011, Roberts et al. 2011, Eyes 2014, Lee and Bond 2015), consist of small sample sizes (Gaines et al. 1997, Jenness et al. 2004, Bond et al. 2009, Clark et al. 2011, Eyes 2014), or examined only short-term effects (Bond et al. 2002, 2009, Clark et al. 2011, 2013, Roberts et al. 2011, Eyes 2014, Lee and Bond 2015, Jones et al. 2016). We attempted to address this ambiguity by analyzing northern spotted owl responses to wildfire using a robust analytical method, the Before-After-ControlImpact (BACI) design, and a wide range of wildfire severities that burned across a 21-yr period. We hypothesized that the degree to which spotted owls would be influenced by wildfire would be contingent on disturbance intensity (i.e., wildfire severity).

In this study, we capitalized on a natural experiment during a 26-yr study of the population ecology of northern spotted owls in the Klamath Province to examine how wildfire influenced apparent survival and recruitment. Our data was not confounded with salvage logging because post-fire salvage logging did not occur in our study area. Because fires occurred on different northern spotted owl territories between 1987 and 2008, we were able to utilize a BACI design to compare pre- and postfire survival and recruitment at territories affected by wildfire (treatments) with territories unaffected by fire (control). Based on the natural fire regime in the Klamath province, we predicted lower severity wildfires would have minimal effects on northern spotted owl populations while higher severity wildfires would negatively affect those populations.

\section{Methods}

\section{Field surveys}

Our field methods are detailed in Franklin et al. (1996, 2000). Briefly, we surveyed two study areas (Fig. 1b) using vocal surveys to detect northern spotted owls annually between April and August from 1987 to 2012. The first was a contiguous $292 \mathrm{~km}^{2}$ area in Humboldt and Trinity counties, California, which we surveyed entirely. The second study area consisted of 34 territories surveyed annually in Humboldt, Trinity, Siskiyou, and Mendocino counties, California. Unlike the first study area, we did not survey the matrix lands between territories in the second; all other survey methods were the same between study areas. Owls located and captured were marked with a uniquely numbered U.S. Geological Survey band and a unique colorband combination that allowed for subsequent identification through resighting the colorband.

We defined spotted owl territories following Franklin et al. (2000) where the territory center was defined as the arithmetic mean of all cumulative roost and nest locations within a given territory. We then created a 1,000 m buffer around each territory center to define the territory boundaries where owls might be affected by fire because, 1) it was approximately halfway between $1 / 2$ mean nearest neighbor distance (714 m; Franklin et al. 2000) and home range estimates $(1,381 \mathrm{~m}$; Bingham and Noon 1997) for spotted owls in this region, and 2) Bond et al. (2009) found that foraging California spotted owls (Strix occidentalis occidentalis) selected for all burn severities up to $1,000 \mathrm{~m}$ from their roost. Thus, we considered a territory "affected" by fire if the territory center was within $1,000 \mathrm{~m}$ of a burn perimeter. Within this $1,000 \mathrm{~m}$ buffer, we calculated fire covariates that characterized the extent and severity of wildfire for each affected territory. 
a

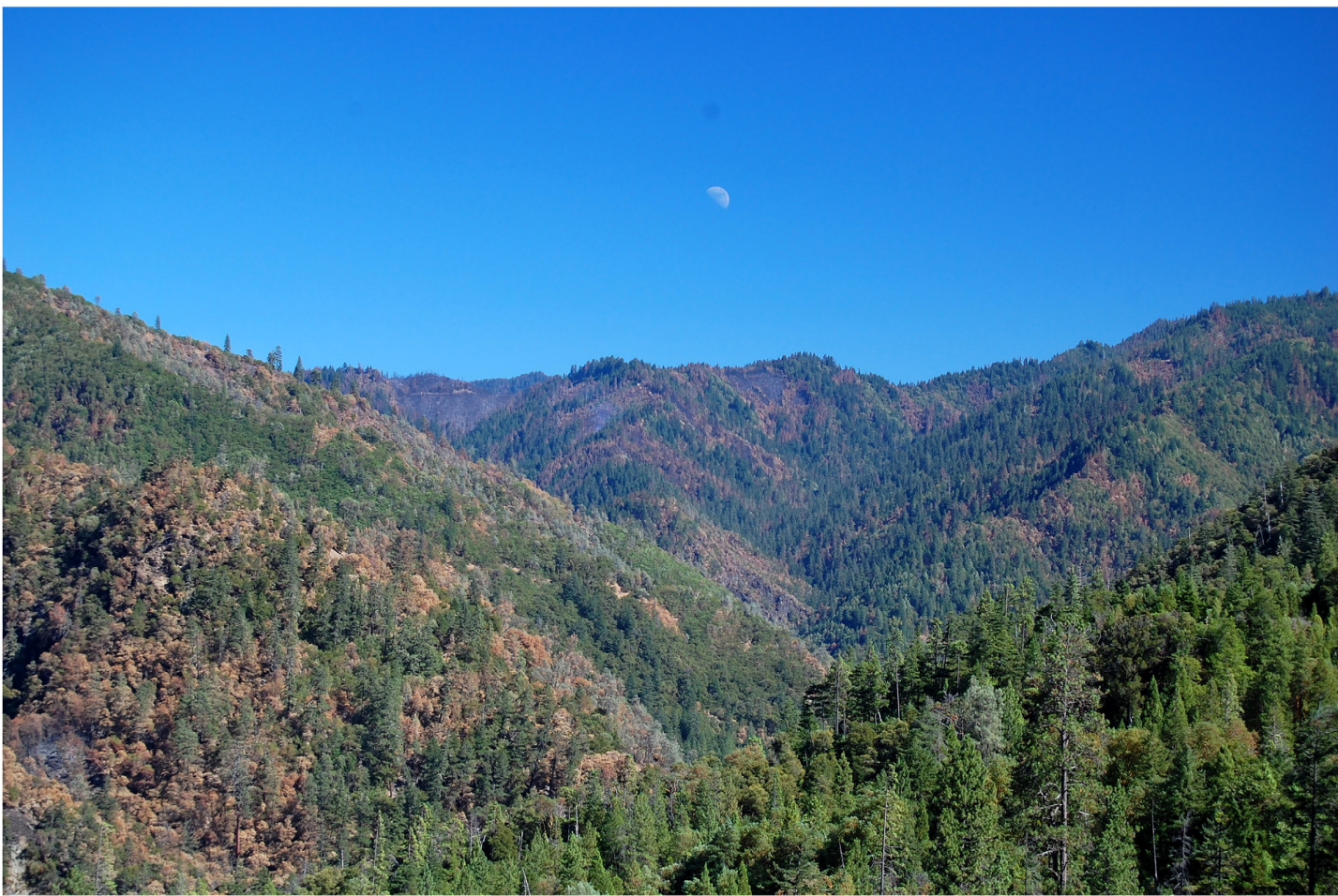

b

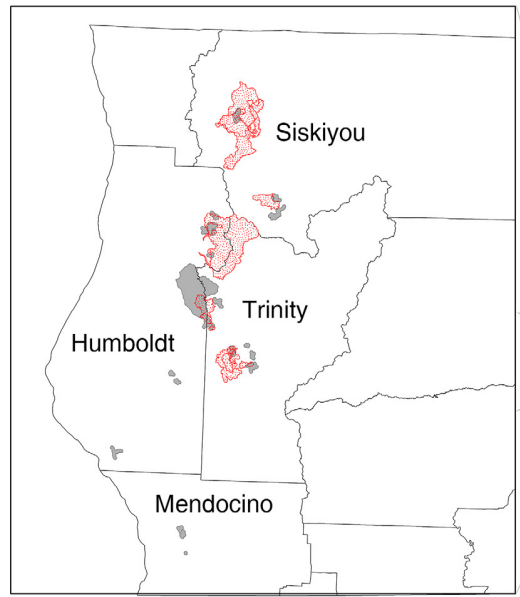

$\mathbf{0} \quad 25 \quad 50 \quad 75100 \mathrm{~km}$
C

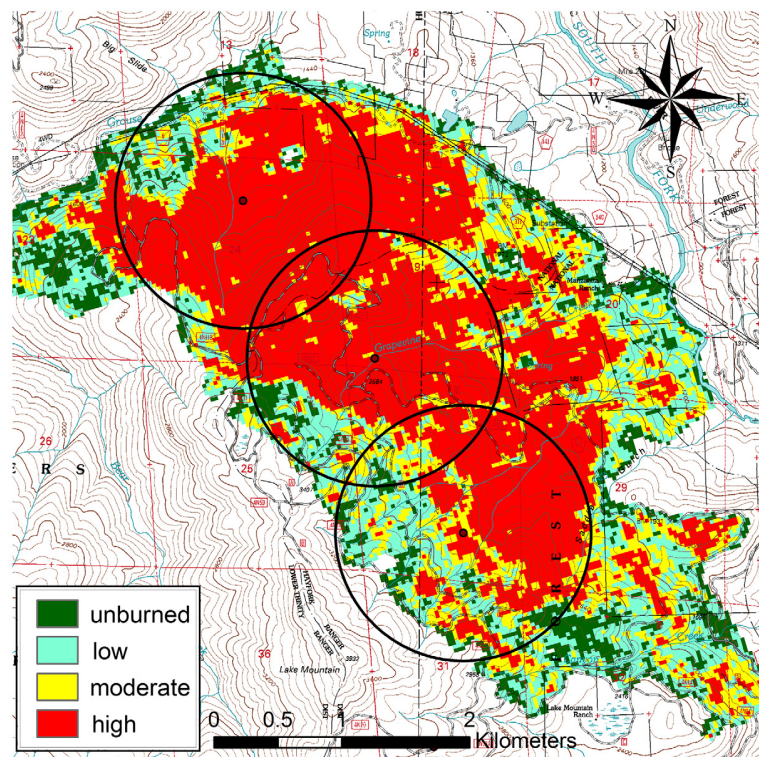

FIG. 1. (a) Landscape typical of the Klamath Province of northwestern California illustrating the patchwork of burn severities created by a mixed-severity fire regime. (b) Location of study area (shaded areas) and burn perimeters of fires (red stippled areas) used to estimate apparent survival and recruitment rates of northern spotted owls. (c) Example of high burn severity from the 2004 Sims Fire that impacted 3 northern spotted owl territories (circles). [Color figure can be viewed at wileyonlinelibrary.com]

\section{Characterization of fire effects}

We used data from the Monitoring Trends in Burn Severity (MTBS) project (Eidenshink et al. 2007) to identify fires that occurred on our study areas from 1987 through 2012. The MTBS project was designed to provide consistent, long-term, nation-wide burn severity information by mapping all large fires across the U.S. ( $>404$ ha in the West) and generating spatial information on burn perimeter and fire severity for each fire. Severity thresholds 
(unburned, low, medium, high) were derived using the delta Normalized Burn Ratio (dNBR; Cocke et al. 2005, Key and Benson 2006, Eidenshink et al. 2007). Post-fire imagery was taken as close as possible to one year after the pre-fire image to minimize variation in plant phenology (Miller and Thode 2007). This value was then converted into discrete burn severity categories: unburned, low severity, moderate severity, or high severity. Burn severity categories were defined based on ground-based methods of estimating ecological fire effects (Key and Benson 2006) that correlate with the satellite-based methods used by the MTBS project. Low severity wildfire was defined as areas that exhibited $>15 \%$ of an area burned with an almost complete combustion of litter, but with $<25 \%$ overstory tree mortality. Conversely, high severity wildfire was defined as areas with a nearly complete combustion of litter and duff, a high degree (35$65 \%$ ) of medium and heavy woody debris consumed and an overstory tree mortality $>75 \%$. Moderate severity fire encompassed everything between low and high severity (Schwind 2007, public communications).

We used the Patch Analyst extension in ArcGIS to calculate annual, individual covariates that characterized the extent and severity of fire within our defined owl territories and were used to represent different hypotheses about the effects of fire on spotted owl survival. We calculated the proportion of each territory that burned at any severity (pBurn) and the distance from each territory center to the nearest burn perimeter (Dist) to characterize the extent of fire within the affected territories. We also calculated the proportion of each territory that burned at low (pLow), moderate (pMod), and high severity (pHigh) fire, and the combined proportions that burned at low and moderate severity (pLowMod), and moderate and high severity (pModHigh) fire. We calculated these latter two covariates because the broad ecological definition of moderate severity fire $(25-75 \%$ canopy tree mortality) resulted in some uncertainty in how it would affect spotted owls. Four of the territories that burned in 2008 also burned in 1987. When calculating covariates for these territories, we combined the fire effects from 1987 and 2008 because we felt that the effects from the 1987 fires were probably still influencing resident spotted owls 21 yr later. Finally, we calculated a fire severity index (FSI; Shaffer and Laudenslayer 2006) where: FSI $=(\mathrm{pLow} \times 1)+(\mathrm{pMod} \times 2)+(\mathrm{pHigh} \times 3)$, in an attempt to summarize the overall burn characteristics within each territory into a single covariate. Thus, FSI represented the hypothesis that an owl's response to wildfire was a function of the cumulative effects of all burn severities within an owl's territory and not the result of any particular level of burn severity. We tested each covariate separately because many of the covariates were highly correlated with each other $(r=0.21-0.98)$. We also examined the linear, quadratic, and pseudothreshold form of each covariate to determine how spotted owl populations respond to changes in the extent and severity of wildfire within their territory.

\section{Estimating survival and recruitment}

We estimated apparent survival (the probability that an individual alive in year $t$ was also alive in year $t+1$, given the individual remained on the study area) of nonjuvenile northern spotted owls (i.e., $\geq 1 \mathrm{yr}$ old) using Cormack-Jolly Seber capture-recapture models (Cormack et al. 1979) and recruitment rates (number of individuals in the population at time $t+1$ per individual in the population at time $t$ ) using Pradel reverse-time Jolly Seber capture-recapture models (Pradel 1996) in program MARK (White and Burnham 1999). These two parameters captured the full dynamic of the treatment (i.e., fire) effect in that apparent survival accounted for both survival and emigration from burned territories (e.g., the reciprocal of survival indicated that the individual either died or left the territory) and recruitment accounted for new immigrants into the affected territories.

We analyzed the capture-recapture data using five groups based on the years when fires occurred (1987, 1999, 2004, 2008, and control group) and the territories affected by the fires in those years. Spotted owls on sites never affected by fire (i.e., territory center $>1,000 \mathrm{~m}$ from a burn perimeter) during the course of the study were assigned to the control group. We did not have prefire data for the 1987 group because that was the first year of surveys at those sites. If a spotted owl moved between treatment and control groups, we truncated its capture history at the last year it was observed in that group, and then began a new capture history the year it showed up in the new group. We used this approach to account for movement between groups because $<5 \%$ of individuals moved between groups.

We used a multi-step modeling process to estimate apparent survival rates of territorial spotted owls using $\mathrm{AIC}_{\mathrm{c}}$ (Burnham and Anderson 2002) to rank models after each step and to determine the best overall model. In the first step, we modeled recapture rates $(p)$ while keeping apparent survival $(\phi)$ unconstrained by group and year $\left(g^{*} t\right)$ to determine the recapture structure with the lowest $\mathrm{AIC}_{\mathrm{c}}$ value. We then used the recapture structure from this model to begin modeling apparent survival. In the second step, we modeled the best time structure for $\phi$ on the control group of owls not affected by fire followed by modeling the best time structure on the pre-fire years of the fire groups. In the third and final step, we modeled the best time structure for the post-fire years of the fire groups. We maintained annual time variation $(g+t)$ in the fire groups while modeling the control group, and in the post-fire years while modeling the prefire years. After determining which overall time model best fit the data, we added the annual, individual covariates to determine what fire characteristics helped explain the observed patterns in spotted owl post-fire survival.

We then estimated group-specific recruitment rates $(f)$ to better capture the occupancy dynamics of territories affected by fire. After developing models for apparent survival, we used the Pradel models (Pradel 1996) in 
program MARK to estimate recruitment rates using the top time structure from the survival analysis above. We used $\mathrm{AIC}_{\mathrm{c}}$ to compare a model with no pre- and post-fire effect on recruitment rates, with a model allowing for different pre- and post-fire effects on recruitment rates.

Lastly, barred owls have been found to negatively affect spotted owl apparent survival, occupancy and colonization rates (Dugger et al. 2016). Barred owl detections on our study areas remained at consistently low levels through the mid-2000s $(\sim 8-13 \%$ of spotted owl territories surveyed had sporadic barred owl detections annually through 2006) and did not begin to increase until 2007, which is a similar timing as the 2008 fires. However, only one of the territories affected by wildfire in 2008 was occupied by barred owls, so we did not consider barred owl presence in our analysis.

\section{RESULTS}

Ten fires ranging in size from 496 ha to 50,386 ha burned through all or portions of 24 of $94(26 \%)$ territories surveyed in our study areas during the course of the study (Table 1). Four of these territories were burned twice in wildfires occurring in 1987 and 2008. Most of the fires were typical of the mixed-severity fire regime of the area (Willis and Stuart 1994, Taylor and Skinner 1998 ) with average proportions of $0.27,0.39,0.19,0.15$ for unburned, low, moderate, and high severity fire, respectively. However, $48 \%$ of the 2004 Sims Fire burned at high severity (Table 1, Fig. 1c).

We used 579 unique encounter histories $\left(n_{1987}=70\right.$; $n_{1999}=18 ; n_{2004}=28 ; n_{2008}=77, n_{\text {control }}=386$ ) to estimate pre- and post-fire apparent survival and recruitment rates. The best model structure for recapture rates $(p)$ included a linear time trend $(\hat{\beta}=-0.068$, 95\% $\mathrm{CI}=-0.094-[-0.043])$ which indicated that recapture rates slowly declined over the course of the study. The best survival model without covariates (Appendix S1: Table S1) indicated that: 1) each group had constant (no time trend) pre-fire estimates of apparent survival that did not differ from each other or the control group $\left(\hat{\varphi}_{\text {control }}=0.83,95 \%\right.$
$\mathrm{CI}=0.81-0.84 ; \quad \hat{\varphi}_{\text {pre } 1999}=0.93, \quad 95 \% \quad \mathrm{CI}=0.83-0.97 ;$ $\hat{\varphi}_{\text {pre2004 }}=0.88, \quad 95 \% \quad \mathrm{CI}=0.81-0.93 ; \quad \hat{\varphi}_{\text {pre2008 }}=0.82$, $95 \% \mathrm{CI}=0.77-0.86$; Fig. 2a), and 2) fire had a strong, significant negative effect on apparent survival for the 2004 and 2008 fire groups (Fig. 2a). Fire also appeared to have a slight negative effect on the 1999 group. However, there was uncertainty about this effect with overlapping confidence intervals for pre- and post-fire survival estimates (Fig. 2a; $\hat{\varphi}_{\text {post1999 }}=0.83,95 \% \mathrm{CI}=0.69-0.91$ ). The 1987 group lacked pre-fire data, but post-fire survival was not different than the control group. There was strong support for this model, which accounted for $>62 \%$ of the Akaike weight (Appendix S1: Table S1).

The best performing model that included the territory-specific fire covariates (Appendix S1: Table S2) included the combined proportion of moderate and high severity fire within $1,000 \mathrm{~m}$ of the owl's activity center $\left(\hat{\beta}_{\mathrm{pModHigh}}=-1.88,95 \% \mathrm{CI}=-3.36-[-0.40]\right)$, indicating that as the combined proportion of moderate and high severity fire increased, apparent survival decreased (Fig. 3). Seven other covariate models were within 2 $\mathrm{AIC}_{\mathrm{c}}$ units of the top-ranked covariate model suggesting some model selection uncertainty (Appendix S1: Table S2). However, all of the competitive covariates (FSI, pMod, pHigh, pBurn, FSI ${ }^{2}$, pModHigh ${ }^{2}$, and Ln (FSI)) supported the same negative association between fire severity and spotted owl survival. Thus, we found a negative relationship between the probability of spotted owls surviving and remaining on a territory and the extent and severity of wildfire within an owl's territory.

The top recruitment model indicated that post-fire recruitment rates were not statistically different from prefire rates or the control group, except for the owls affected by wildfire in 2008 , where recruitment rates substantially increased post-fire (Fig. 2b). Point estimates for the other fire groups increased slightly despite the lack of any statistical significance $\left(\hat{f}_{\text {pre } 1999}=0.10,95 \%\right.$ CI $=0.04-0.22$; $\hat{f}_{\text {post1999 }}=0.12,95 \%$ CI $=0.05-0.24 ; \quad \hat{f}_{\text {pre2004 }}=0.13$, $95 \%$ CI $=0.08-0.21 ; \hat{f}_{\text {post2004 }}=0.17,95 \%$ CI $=0.07-$ 0.37 ), and this slight increase likely contributed to the strong support (Appendix S1: Table S3) for this model.

TABLE 1. Characteristics of wildfires that affected northern spotted owl territories in the Klamath province of northwest California.

\begin{tabular}{lccccccc}
\hline \hline Year & Fire name & Territories affected & Size (ha) & Unburned & Low & Moderate & High \\
\hline 1987 & Cold & $1^{1}$ & 5,988 & 0.43 & 0.40 & 0.13 & 0.04 \\
& Friendly & 1 & 1,406 & 0.24 & 0.39 & 0.25 & 0.12 \\
& Glasgow & 3 & 5,462 & 0.24 & 0.35 & 0.23 & 0.18 \\
& King Titus & $3^{2}$ & 28,892 & 0.36 & 0.42 & 0.15 & 0.06 \\
1999 & Meagram & 2 & 50,386 & 0.24 & 0.41 & 0.19 & 0.16 \\
2004 & Sims & 4 & 1,541 & 0.10 & 0.21 & 0.20 & 0.48 \\
2008 & Hell's Half & 9 & 6,016 & 0.39 & 0.33 & 0.18 & 0.10 \\
& Slide & 1 & 496 & 0.44 & 0.28 & 0.18 & 0.10 \\
& Lime & $1^{1}$ & 11,021 & 0.32 & 0.48 & 0.16 & 0.04 \\
& Panther & $3^{2}$ & 28,915 & 0.16 & 0.36 & 0.24 & 0.23 \\
\hline
\end{tabular}

Note: Superscripts correspond to territories that initially burned in 1987 and were reburned in 2008. 


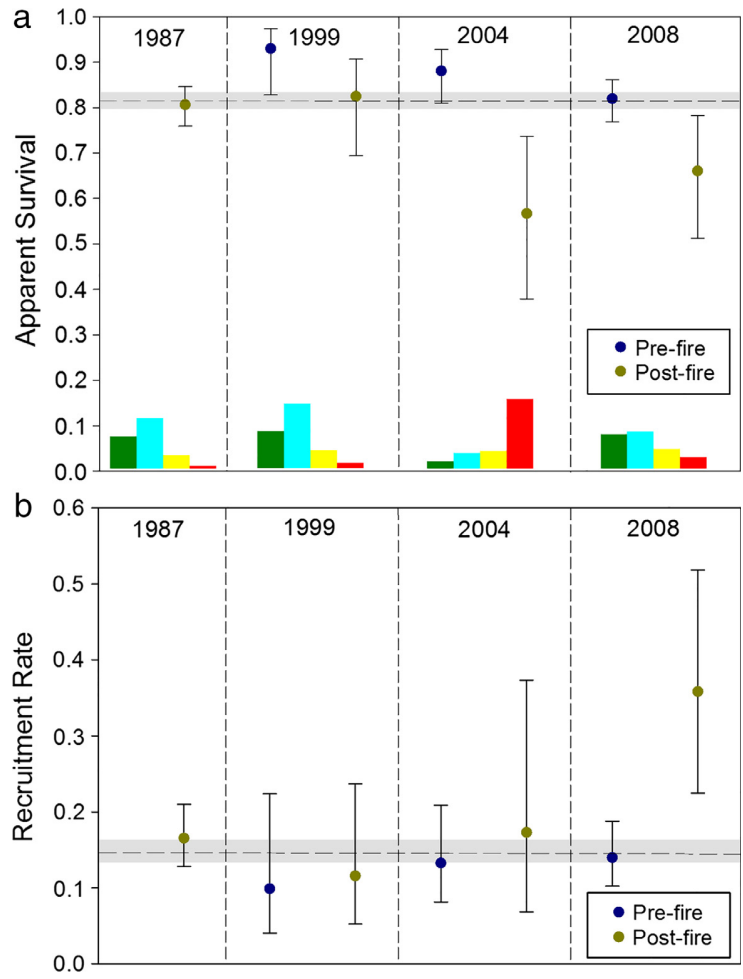

FIG. 2. Point estimates and their $95 \%$ confidence intervals of pre- and post-fire apparent survival (a) and recruitment rates (b) for the different fire groups. The point estimate and 95\% confidence interval for the control group is shown in each graph as the dashed horizontal line and shaded bar. Bar graphs in Fig. 2a show the comparative amount of unburned (green), low (blue), moderate (yellow), and high (red) severity fire within the spotted owl territories for each group. [Color figure can be viewed at wileyonlinelibrary.com]

The increase in recruitment rates for owls affected by wildfire in 2008 suggested that immigration to these sites increased post-fire, which was partially responsible for maintaining occupancy on some of these territories.

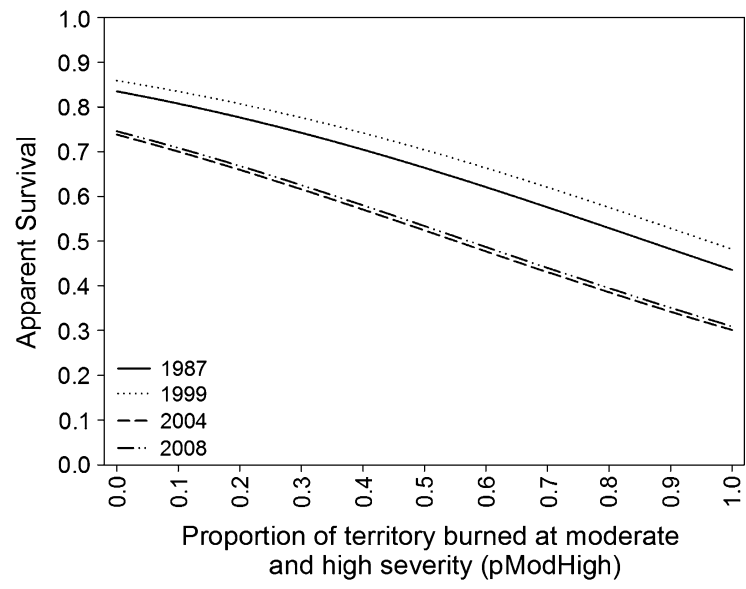

FIG. 3. bResults from the top covariate model showing the influence of the combined proportion of moderate and high severity fire (pModHigh) on northern spotted owl apparent survival.

\section{Discussion}

Wildfires on our study area occurred across different years, affected different territories and had different burn characteristics, which allowed us to implement a retrospective BACI mark-recapture analysis under a natural experimental design and incorporate covariates that characterized the extent and severity of each wildfire within spotted owl territories. Our results suggest that the degree to which northern spotted owls are influenced by wildfire is partially dependent on the characteristics of that wildfire. Wildfires with different mixtures of burn severity represented a continuum of effects where the predominantly lower severity fires in 1987 and 1999 were associated with minimal impacts on survival and recruitment, moderate to higher severity fires in 2008 were associated with a reduction in survival but allowed for increased recruitment, and the predominantly higher severity fire in 2004 was associated with a large reduction in survival with minimal effect on recruitment (Fig. 2). The 2004 Sims Fire (Table 1, Fig. 1a) was particularly severe, burning for $5 \mathrm{~d}$ during above-normal temperatures $\left(>38^{\circ} \mathrm{C}\right)$; conditions correlated with increased amounts of high severity fire (Agee 1993, Pettit and Naiman 2007, Perry et al. 2011). Nesting and roosting habitat of northern spotted owls is closely associated with mature and old-growth forests that include a multi-layered canopy, high canopy cover $(>70 \%)$, large amounts of course woody debris, and a high basal area of conifers (Forsman et al. 1984, Blakesley et al. 1992, LaHaye and Gutiérrez 1999). Thus, it is likely that postfire habitat conditions become unsuitable for nesting and roosting by spotted owls following wildfires with large, extensive patches of high severity fire (e.g., 2004 Sims Fire; Jones et al. 2016). Although spotted owls may use high severity patches (Bond et al. 2009, 2016), there is likely a threshold level of high severity fire effects beyond which habitat suitability is appreciably reduced (Lee et al. 2013, Jones et al. 2016).

Following this gradient from lower to higher wildfire severities, the 2008 fires provided us with unique insight into the effects of wildfire on northern spotted owl population dynamics. Post-fire apparent survival of owls affected by wildfire in 2008 decreased (Fig. 2a), while post-fire recruitment rates increased (Fig. 2b) which effectively compensated for the lower survival and created a situation in which territories remained mostly occupied, but with higher turnover. Increased turnover in these territories suggests that habitat quality was reduced post-fire, resulting in marginal habitat that was only capable of supporting owls temporarily before they either emigrated or died (e.g., Redpath 1995, Winker et al. 1995). Thus, the effects of wildfires on wildlife populations goes beyond the individual, territory-scale effects and may also depend on the surrounding landscape (Franklin et al. 2002), particularly in a region such as the Klamath Province where mixed-severity fire creates a patchwork of seral stages and habitat quality. The 
resulting landscape may therefore be comprised of some areas with suitable habitat conditions for spotted owls and a sufficient number of individuals to provide new recruits (sources) to areas that burned more severely and are marginally capable of supporting individuals (sinks; Pulliam 1988).

This concept is supported by previous research on our study area (Franklin et al. 2000) on spotted owl habitat quality where it was found that spotted owls occupied a continuum of habitats that range from low to high quality with high quality territories acting as sources and low quality territories acting as sinks. If moderate and high severity fire in 2008 reduced the amount of older forest, a key component of nesting and roosting habitat for spotted owls, source territories could become sink territories that are being supported by immigration of individuals dispersing from nearby areas of higher quality habitat (e.g., areas that experienced less high severity fire; Pulliam 1988, Franklin et al. 2000).

Optimal habitat for northern spotted owls in the Klamath Province appears to be composed of a mosaic of late seral stages for nesting and roosting (conditions that are maintained by low severity fire) with smaller, early seral stages (conditions created by high severity fire) where the owl's primary prey species, the dusky-footed woodrat (Neotoma fuscipes), is more abundant (Sakai and Noon 1993, Ward et al. 1998). Thus, it appears that northern spotted owls inhabiting the Klamath Province have capitalized on this seral stage patchwork created by the dominant disturbance regime of the region (mixedseverity wildfire) by nesting and roosting in areas that experienced low severity fire, and foraging across all seral stages including early seral stages created by high severity fire where woodrats become more abundant (Sakai and Noon 1993, 1997, Ward et al. 1998, see Bond et al. 2009).

Patterns of mixed-severity fire in the Klamath Province are influenced by complex interactions between the region's topography, climate, and fuels. The result is a dynamic patchwork of seral stages, but one in which some generalities can be made. Topography and climate were historically the two major determinants of fire severity in the region and have been relatively stable during the recent past, helping to enforce a pattern wherein north and east slopes are usually dominated by lower severity wildfire and south and west slopes generally experience higher severity fire (Taylor and Skinner 1998). Similarly, because of their relatively high fuel moisture content, riparian areas tend to dampen the spread of fires (Pettit and Naiman 2007). However, during periods of extreme fire weather, these regulating mechanisms can break down resulting in large patches of high severity fire which can be detrimental to spotted owls (Jones et al. 2016). Summers in the Pacific Northwest are predicted to become longer, hotter and drier; conditions that are correlated with increased fire activity in the West (Wimberly and Liu 2014, Westerling 2016). Thus, a changing disturbance regime in which wildfires increase in extent and intensity suggests the long-term persistence of viable northern spotted owl populations may be compromised (Johnstone et al. 2016), especially when combined with multiple recent stressors, such as habitat removal due to logging and increased competition from the recent invasion of nonnative barred owls.

\section{ACKNOWLEDGMENTS}

Funding was provided by the U.S. Forest Service, Region 5. JR, AF and PC collected field data. JR designed the study and performed the analyses. AF and PC contributed to the study design. AF oversaw the analyses. JR wrote the first version of the manuscript and all coauthors contributed substantially to all revisions. We thank two anonymous reviewers for their excellent suggestions and edits, which substantially contributed to the final manuscript.

\section{Literature Cited}

Abatzoglou, J. T., and A. P. Williams. 2016. Impact of anthropogenic climate change on wildfire across Western US forests. Proceedings of the National Academy of Sciences of the United States of America 113:11770-11775.

Agee, J. K. 1993. Fire ecology of Pacific Northwest forests. Island Press, Washington, D.C.

Blakesley, J. A., A. B. Franklin, and R. J. Gutiérrez. 1992. Spotted owl roost and nest site selection in Northwestern California. Journal of Wildlife Management 56:388-392.

Bingham, B. B., and B. R. Noon. 1997. Mitigation of habitat "take": application to habitat conservation planning. Conservation Biology 11:127-139.

Bond, M. L., R. J. Gutiérrez, A. B. Franklin, W. S. Lahaye, C. A. May, and M. E. Seamans. 2002. Short-term effects of wildfires on spotted owl survival, site fidelity, mate fidelity, and reproductive success. Wildlife Society Bulletin 30:10221028.

Bond, M. L., D. E. Lee, R. B. Siegel, and J. P. Ward. 2009. Habitat use and selection by California spotted owls in a postfire landscape. Journal of Wildlife Management 73:11161124.

Bond, M. L., C. Bradley, and D. E. Lee. 2016. Foraging habitat selection by California spotted owls after fire. Journal of Wildlife Management 80:1290-1300.

Burnham, K. P., and D. R. Anderson. 2002. Model selection and multi-model inference: a practical information-theoretic approach. Second edition. Springer, New York.

Clark, D. A., R. G. Anthony, and L. S. Andrews. 2011. Survival rates of northern spotted owls in post-fire landscapes of Southwest Oregon. Journal of Raptor Research 45:38-47.

Clark, D. A., R. G. Anthony, and L. S. Andrews. 2013. Relationship between wildfire, salvage logging, and occupancy of nesting territories by northern spotted owls. The Journal of Wildlife Management 77:672-688.

Cocke, A. E., P. Z. Fulé, and J. E. Crouse. 2005. Comparison of burn severity assessments using differenced normalized burn ratio and ground data. International Journal of Wildland Fire 14:189-198.

Cormack, R. M., G. P. Patil, and D. S. Robson. 1979. Models for capture-recapture. Pages 217-255 in R. M. Cormack, G. P. Patil, and D. S. Robson, editors. Sampling biological populations. International Co-operative Publishing House, Fairland, Maryland.

Davis, R. J., K. M. Dugger, S. Mohoric, L. Evers, and W. C. Aney. 2011. Northwest Forest Plan-The First 15 Years 
(1994-2008): Status and Trends of Northern Spotted Owl Populations and Habitats. Pages 1-156 U.S. Department of Agriculture General Technical Report PNW-GTR-850. U.S. Department of Agriculture.

Donato, D. C., J. B. Fontaine, J. L. Campbell, W. D. Robinson, J. B. Kauffman, and B. E. Law. 2009. Conifer regeneration in stand-replacement portions of a large mixed-severity wildfire in the Klamath-Siskiyou Mountains. Canadian Journal of Forest Research 39:823-838.

Dugger, K. M., et al. 2016. The effects of habitat, climate, and barred owls on long-term demography of northern spotted owls. The Condor 118:57-116.

Eidenshink, J., B. Schwind, K. Brewer, Z. Zhu, B. Quayle, and S. Howard. 2007. A project for monitoring trends in burn severity. Fire Ecology 3:3-21.

Eyes, S. A. 2014. The Effects of Fire Severity on California Spotted Owl Habitat Use Patterns. Thesis, Humboldt State University, Arcata, California, USA.

Forsman, E. D., E. C. Meslow, and H. M. Wight. 1984. Distribution and biology of the spotted owl in Oregon. Wildlife Monographs 87:64.

Franklin, A. B., D. R. Anderson, E. D. Forsman, K. P. Burnham, and F. W. Wagner. 1996. Methods for collecting and analyzing demographic data on the northern spotted owl. Studies in Avian Biology 17:12-22.

Franklin, A. B., D. R. Anderson, R. J. Gutierrez, and K. P. Burnham. 2000. Climate, habitat quality, and fitness in northern spotted owl populations in Northwestern California. Ecological Monographs 70:539-590.

Franklin, A. B., B. R. Noon, and T. L. George. 2002. What is habitat fragmentation? Studies in Avian Biology 25: 20-29.

Fraterrigo, J. M., and J. A. Rusak. 2008. Disturbance-driven changes in the variability of ecological patterns and processes. Ecology Letters 11:756-770.

Gaines, W. L., R. A. Strand, and S. D. Piper. 1997. Effects of the hatchery complex fires on northern spotted owls in the Eastern Washington cascades. Pages 123-129 in J. M. Greenlee, editor. Fire effects on rare and endangered species and habitats. Coure d' Alene, Idaho.

Halofsky, J. E., et al. 2011. Mixed-severity fire regimes: lessons and hypotheses from the Klamath-Siskiyou ecoregion. Ecosphere 2:1-19.

Hessburg, P. F., et al. 2016. Tamm review: management of mixed-severity fire regime forests in Oregon, Washington, and Northern California. Forest Ecology and Management 366:221-250.

Jenness, J. S., P. Beier, and J. L. Ganey. 2004. Associations between forest fire and Mexican spotted owls. Forest Science 50:765-772.

Johnstone, J. F., et al. 2016. Changing disturbance regimes, ecological memory, and forest resilience. Frontiers in Ecology and the Environment 14:369-378.

Jones, G. M., R. J. Gutiérrez, D. J. Tempel, S. A. Whitmore, W. J. Berigan, and M. Z. Peery. 2016. Megafires: an emerging threat to old-forest species. Frontiers in Ecology and the Environment 14:300-306.

Key, C. H., and N. C. Benson. 2006. Landscape assessment (LA): Sampling and Analysis Methods. Pages 1-55 USDA Forest Service General Technical Report RMS-GTR-164CD. U.S. Department of Agriculture.

LaHaye, W. S., and R. J. Gutiérrez. 1999. Nest sites and nesting habitat of the northern spotted owl in Northwestern California. The Condor 101:324-330.

Lee, D. E., and M. L. Bond. 2015. Occupancy of California spotted owl sites following a large fire in the Sierra Nevada, California. The Condor 117:228-236.
Lee, D. E., M. L. Bond, and R. B. Siegel. 2012. Dynamics of breeding-season site occupancy of the California spotted owl in burned forests. The Condor 114:792-802.

Lee, D. E., M. L. Bond, M. I. Borchert, and R. Tanner. 2013. Influence of fire and salvage logging on site occupancy of spotted owls in the San Bernardino and San Jacinto Mountains of Southern California. The Journal of Wildlife Management 77:1327-1341.

Liu, Y., S. L. Goodrick, and J. A. Stanturf. 2013. Future U.S. wildfire potential trends projected using a dynamically downscaled climate change scenario. Forest Ecology and Management 294:120-135.

Lutz, J. A., J. W. van Wagtendonk, A. E. Thode, J. D. Miller, and J. F. Franklin. 2009. Climate, lightning ignitions, and fire severity in Yosemite National Park, California, USA. International Journal of Wildland Fire 18:765-774.

Miller, J. D., and A. E. Thode. 2007. Quantifying burn severity in a heterogeneous landscape with a relative version of the delta Normalized Burn Ratio (dNBR). Remote Sensing of Environment 109:66-80.

Miller, J. D., H. D. Safford, M. Crimmins, and A. E. Thode. 2009. Quantitative evidence for increasing forest fire severity in the Sierra Nevada and Southern Cascade Mountains, California and Nevada, USA. Ecosystems 12:16-32.

Miller, J. D., C. N. Skinner, H. D. Safford, E. E. Knapp, and C. M. Ramirez. 2012. Trends and causes of severity, size, and number of fires in Northwestern California, USA. Ecological Applications 22:184-203.

Odion, D. C., E. J. Frost, J. R. Strittholt, H. Jiang, D. A. Dellasala, and M. A. Moritz. 2004. Patterns of fire severity and forest conditions in the Western Klamath Mountains, California. Conservation Biology 18:927-936.

Perry, D. A., P. F. Hessburg, C. N. Skinner, T. A. Spies, S. L. Stephens, A. H. Taylor, J. F. Franklin, B. McComb, and G. Riegel. 2011. The ecology of mixed severity fire regimes in Washington, Oregon, and Northern California. Forest Ecology and Management 262:703-717.

Pettit, N. E., and R. J. Naiman. 2007. Fire in the riparian zone: characteristics and ecological consequences. Ecosystems 10:673-687.

Pradel, R. 1996. Utilization of capture-mark-recapture for the study of recruitment and population growth. Biometrics 52:703-709.

Pulliam, H. R. 1988. Sources, sinks, and population regulation. American Naturalist 132:652-661.

Redpath, S. M. 1995. Habitat fragmentation and the individual - Tawny Owls Strix Aluco in woodland patches. Journal of Animal Ecology 64:652-661.

Roberts, S. L., J. W. van Wagtendonk, A. K. Miles, and D. A. Kelt. 2011. Effects of fire on spotted owl site occupancy in a late-successional forest. Biological Conservation 144:610-619.

Rykiel, E. J. 1985. Towards a definition of ecological disturbance. Australian Journal of Ecology 10:361-365.

Sakai, H. F., and B. R. Noon. 1993. Dusky-footed woodrat abundance in different-aged forests in Northwestern California. The Journal of Wildlife Management 57:373-382.

Sakai, H. F., and B. R. Noon. 1997. Between-habitat movement of dusky-footed woodrats and vulnerability to predation. Journal of Wildlife Management 61:343-350.

Schwind, B. (compiler) 2007. Monitoring Trends in Burn Severity: Report on the 2004 Mapped Fires. Available online: http://svinetfc4.fs.fed.us/mtbs/. Accessed 28 December 2016.

Shaffer, K. E., and W. F. Laudenslayer Jr. 2006. Fire and Animal Interactions. Pages 118-144 in N. G. Sugihara, J. W. van Wagtendonk, K. E. Shaffer, J. Fites-Kaufman, and A. E. Thode, editors. Fire in California's ecosystems. University of California Press, Berkeley, California. 
Skinner, C. N., A. H. Taylor, and J. K. Agee. 2006. Klamath Mountains Bioregion. Pages 170-194 in N. G. Sugihara, J. W. van Wagtendonk, J. Fites-Kaufmann, K. E. Shaffer, and A. E. Thode, editors. Fire in California's ecosystems. University of California Press, Berkeley, California.

Stephens, S. L. 2005. Forest fire causes and extent on United States forest service lands. International Journal of Wildland Fire 14:213-222.

Taylor, A. H., and C. N. Skinner. 1998. Fire history and landscape dynamics in a late-successional reserve, Klamath Mountains, California, USA. Forest Ecology and Management 111:285-301.

Thomas, J. W., E. D. Forsman, J. B. Lint, E. C. Meslow, B. R. Noon, and J. Verner. 1990. A Conservation Strategy for the Northern Spotted Owl: Report of the Interagency Scientific Committee to Address the Conservation of the Northern Spotted Owl. USDA Forest Service, USDI Bureau of Land Management, Fish and Wildlife Service, and National Park Service, Portland, OR.

USFWS. 2011. Final Revised Recovery Plan for the Northern Spotted Owl (Strix occidentalis caurina). Pages 1-258 U.S. Fish and Wildlife Service. Portland, OR.
Ward, J. P., R. J. Gutiérrez, and B. R. Noon. 1998. Habitat selection by northern spotted owls: the consequences of prey selection and distribution. The Condor 100:79-92.

Westerling, A. L. 2016. Increasing Western US forest wildfire activity: sensitivity to changes in the timing of spring. Philosophical transactions of the Royal Society of London. Series B, Biological Sciences 371:717-728.

Whitakker, R. H. 1960. Vegetation of the Siskiyou Mountains, Oregon and California. Ecological Monographs 30:279338.

White, G. C., and K. P. Burnham. 1999. Program MARK: survival estimation from populations of marked animals. Bird Study 46:S120-S139.

Willis, R. D., and J. D. Stuart. 1994. fire history and stand development of a Douglas-Fir/Hardwood forest in Northern California. Northwest Science 68:205-212.

Wimberly, M. C., and Z. Liu. 2014. Interactions of climate, fire, and management in future forests of the Pacific Northwest. Forest Ecology and Management 327:270-279.

Winker, K., J. H. Rappole, and M. A. Ramos. 1995. The use of movement data as an assay of habitat quality. Oecologia $101: 211-216$

\section{SUPPORTING INFORMATION}

Additional supporting information may be found in the online version of this article at http://onlinelibrary.wiley.com/doi/ 10.1002/ecy.1805/suppinfo 